\title{
Vagal Paraganglioma
}

\author{
Elisabetta Zanoletti, M.D. ${ }^{1}$ and Antonio Mazzoni, M.D.,
}

\section{ABSTRACT}

Objectives: To report the outcomes of surgical treatment of vagal paragangliomas and to define a management protocol. Design: A retrospective case series. Patients and methods: Sixteen consecutive patients with vagal paragangliomas managed by surgical resection using a cervicoparotid approach and pericapsular dissection using microsurgical techniques between 1990 and 2003. Results: All patients either had or developed a vagal palsy. Additional cranial nerve deficits were sustained in 8 patients. No patients died as a result of surgery or from their disease. Conclusions: The technique used and described in this article allowed adequate exposure of the retrostyloid parapharyngeal space for the safe removal of all vagal tumors in this series. Careful consideration must be given to the likely natural progression of these tumors before committing to surgical resection. This is particularly important in patients with multifocal disease.

KEYWORDS: Vagal paragangliomas, microsurgical technique, parapharyngeal space tumors

Vagal paragangliomas are rare tumors that develop in the retrostyloid compartment of the parapharyngeal space. They arise from an island of paraganglion tissue derived from the neural crest that is located on the vagus nerve. Very occasionally vagal paragangliomas develop on the more distal part of the nerve. The growth of these tumors is very variable: some grow upward toward the skull base while others extend down into the neck. This disease is often monofocal but it may also be part of a multifocal disease that develops in either a metachronous or synchronous fashion. Advances in imaging have aided the diagnosis and assessment of this disease. The surgical management of this condition is associated with significant morbidity and this has prompted an expectant policy to be adopted in some patients. $^{1-5} \mathrm{~A}$ difficult balance has to be struck between the effect of surgical intervention and the dangers of allowing the disease to progress. The difficulty becomes more evident in patients with multifocal disease.

\footnotetext{
${ }^{1}$ ENT Unit, Department of Neurological and Neurosurgical Sciences, Ospedali Riuniti, Bergamo, Italy; ${ }^{2}$ Gruppo Otologico, Casa di Cura Piacenza, Piacenza, Italy.

Address for correspondence and reprint requests: Antonio Mazzoni, M.D., ENT Unit, Department of Neurological and Neurosurgical Sciences, Ospedali Riuniti, via Valverde 33, 24123 Bergamo, Italy. E-mail: antonio.mazzoni@libero.it.
}

Skull Base 2006;16:161-168. Copyright (C) 2006 by Thieme Medical Publishers, Inc., 333 Seventh Avenue, New York, NY 10001, USA. Tel: +1(212) 584-4662.

Received: December 2, 2005. Accepted after revision: December 13, 2005. Published online: August 21, 2006.

DOI 10.1055/s-2006-949519. ISSN 1531-5010. 


\section{CASE DETAILS}

Sixteen patients with vagal paragangliomas underwent surgical resection between 1990 and 2003 . There were 6 males and 10 females with a mean age of 40 years at the time of diagnosis (range, 25 to 74 years; median, 40 years). In 4 cases, the vagal paraganglioma extended through the jugular foramen into the middle ear cleft and in another patient it was part of multifocal, familial disease.

Preoperative diagnosis was made on the basis of a clinical examination and imaging data. In 13 patients, both MRI and CT were acquired while CT images were available in the remaining 3 patients. Diagnostic carotid angiography was performed in all followed by embolization in 2 patients with tumors confined to the neck and in all with disease that extended through the skull base (Figs. 1,2).

Preoperative cranial nerves deficits were sustained by five patients (Table 1): a solitary vagal deficit in three patients and a combination of ninth, tenth, eleventh, and twelfth cranial nerve deficits in the other two patients.

All the patients were operated on with a microsurgical technique, following a protocol already set for tumors of the parapharyngeal space. The procedure was a pericapsular dissection through a cervicoparotid approach. The diagnosis

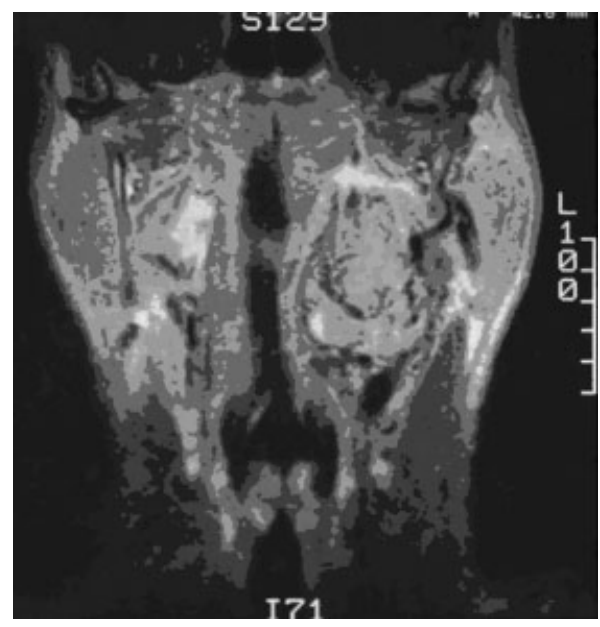

Figure 1 T1-coronal MRI of a vagal paraganglioma. MRI, magnetic resonance image.

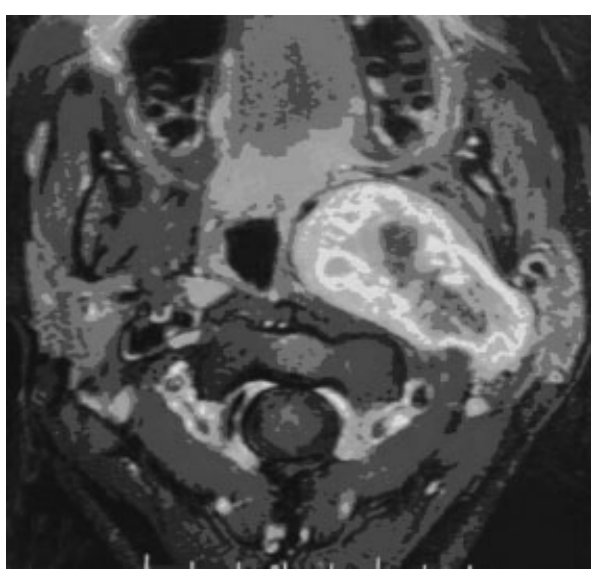

Figure 2 T1-axial MRI of the same case. The internal carotid artery is displaced medially and anteriorly by the tumor; the lumen of the oropharynx is reduced. MRI, magnetic resonance image.

was confirmed by histological examination in every case. The patients were followed up with contrast and fat-saturated MRI at 1,3, and 5 years after surgery. Those patients with multifocal disease also had carotid angiography.

\section{SURGICAL TECHNIQUE}

The operation begins with exposure of the sternocleidomastoid and digastric muscles, the parotid and submandibular glands, and the hyoid bone though a cervicoparotid incision. ${ }^{1,4-7}$ Access to the retrostyloid space is achieved by anterior displacement of the mandible and cranial retraction of the digastric and styloid muscles. The facial nerve is identified and, when the tumor extends to the skull base, is traced peripherally to its third division branches. The common, internal, and external carotid arteries, internal jugular vein, and the ninth, tenth, and twelfth cranial nerves are identified in the neck.

A thin fibrous fascial envelope covers the vagus nerve, the tumor, and the internal carotid artery and plays an important role in the microsurgical approach. The fascia is opened at the lower pole of the tumor and dissected away to expose the 


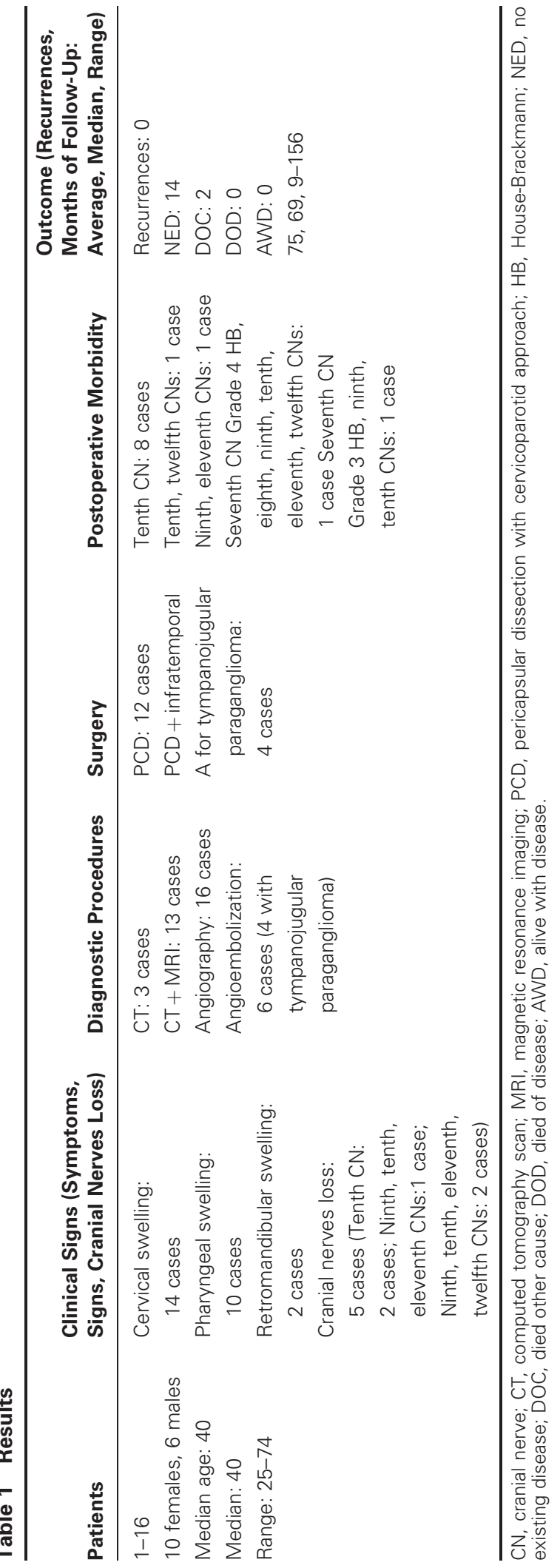


capsular surface of the tumor. Further dissection in the plane of the interface between tumor and fascia leaves the neurovascular structures in place. On the internal carotid artery, the dissection runs between the adventitia of the artery and the tumor. A semisharp dissector (Freer nose dissector) is used for this step. Dissection of the tumor from the internal carotid artery takes place along the posterior aspect of the tumor from below toward the superior pole. The vagus is identified at both the superior and inferior poles of the mass and is dissected using a similar technique. When the nerve becomes indistinguishable from the tumor, it is cut at its superior and inferior pole and removed together with the mass. If the tumor enters the skull base at the jugular foramen, two options are feasible. The sphenoid spine and a few millimeters of bone around the jugular foramen and the carotid canal can be exposed and drilled away to allow a very limited extension of tumor into the jugular foramen to be removed. Or, the conservative petro-occipitaltrans-sigmoid (POTS) ${ }^{8}$ or the transvertebro-occipital access ${ }^{9,10}$ may be used for a larger exposure and removal of a bigger extension. More extensive disease demands an infratemporal type $\mathrm{A}$ approach and this can also be used if there is a concomitant tympanojugular paraganglioma. ${ }^{11}$

\section{RESULTS}

A cervicoparotid appoach with pericapsular microsurgical dissection of the tumor was performed in all the cases. In four patients it was combined with an infratemporal type A procedure for the synchronous resection of a tympanojugular paraganglioma.

All of the 16 patients lost the vagus nerve. Eleven of these deficits were caused by surgical resection while in the other 5 cases established deficits were present before surgery. In 8 patients, cranial nerve deficits amounted to an isolated vagal palsy; in 1 patient the vagal palsy was associated with a hypoglossal deficit; in another, with glossopharyngeal and accessory deficits also. Postoperative mixed nerves palsies developed in the 2 cases of tympanojugular paragangliomas with no preoperative loss. In 1 patient, postoperative thrombosis of the internal carotid artery developed which resulted in a slight leg weakness.

All patients were followed up for a mean period of 75 months (median, 69 months; range, 9 to 156 months). No patient was lost to follow-up. Our data in December 2004 showed that $14 \mathrm{pa}^{-}$ tients were disease free and that 2 patients had died from other causes - a myocardial infarct in one patient and a cerebrovascular accident in the other, 6 months and 3 years after surgery, respectively.

\section{DISCUSSION}

Vagal paragangliomas account for 5\% of all head and neck paragangliomas with an annual incidence of 1 per 100,000 population. There is a female predominance. ${ }^{1-5}$ The mean reported age at diagnosis is 45 years. Vagal paraganglioma can be solitary, bilateral, and either unilateral or bilateral associated with multiple paragangliomas. The incidence of multifocal tumors in patients without a family history is around $10 \%$, whereas the incidence of multiple paragangliomas rises to 30 to $40 \%$ in those with a positive family history. ${ }^{3-5,12,13}$

Familial cases account for 40 to $50 \%^{3}$ of vagal paragangliomas and the diagnosis of these tumors is made at a younger age. Recent studies ${ }^{3}$ show that the development of the disease has a genetic basis linked to a double mutation occurring in the alleles of chromosome 11, where the tumor suppressor PGL- 1 gene is located. As the transmission of the mutation is an autosomal dominant function, the relatives of patients affected by multiple paragangliomas should be submitted to a screening protocol. This should be repeated every 5 years in those in whom tumors are not found. DNA analysis is possible in some, where the mutation is known and can be extremely reliable. ${ }^{3}$ It offers the attractive possibility of a sensitive screen before clinical expression of the disease is evident. 
The natural history of vagal paragangliomas is not entirely known. Morbidity associated with these tumors is unpredictable and is associated with loss of vagal function which might be bilateral.

The necessity to prevent additional cranial nerve deficits influences the therapeutic approach. There is certainly a mortality associated with disease progression and its treatment. Malignant paragangliomas are also a recognized cause of death from regional and distant metastases. ${ }^{14}$

Surgical morbidity associated with vagal deficits is unavoidable. Both our experience and that reported in the literature show that vagal function cannot be preserved even when the nerve is anatomically intact.

There were two cases of postoperative ninth, eleventh, and twelfth cranial nerves deficits caused by surgical trauma. The other postoperative ninth, eleventh, and twelfth cranial nerves deficits developed in four patients who had synchronous tympanojugular paragangliomas.

In our experience the preoperative diagnosis of vagal paraganglioma was accurate.

Angiography was added to our investigative protocol to detect multifocal disease, appreciate the integrity of the circle of Willis, and evaluate the state of the internal carotid artery in terms of atherosclerosis. ${ }^{12,15}$ For the latter purpose, an echoe-Doppler investigation may give adequate information.

Preoperative imaging was accurate and extremely helpful in planning the pericapsular dissection of the tumor. ${ }^{16-18}$ It also distinguished between other parapharyngeal tumors such as pleomorphic adenoma and schwannoma, for which an entirely different approach would have been appropriate. In our experience, the microsurgical technique allowed a safe dissection along difficult planes and delicate structures and increased the confidence of the surgeon. Neither repair nor grafts of the internal carotid artery were necessary. Thrombosis of the internal carotid artery in one of our patients may have been caused by aggressive handling of the artery. We learned from this experience not to retract or displace the artery too much and to proceed with a semi-sharp dissection, performing every maneuver on the tumor and not the artery.

Treatment planning for these patients can be fraught with problems and the major dilemma is the choice between surgery and observation. Radiotherapy as a realistic alternative lacks an evidence base. ${ }^{2-6,17,19}$ The decision must be based on several factors that include the age of the patient, the preoperative status of the vagus, and the size and growth rate of the tumor. Multifocal disease may modify the management plan radically. In this respect there are some basic facts that should be considered:

1. The natural morbidity of glossopharyngeal and vagal deficits is better tolerated than that caused by surgery.

2. The elderly do not compensate well for glossopharyngeal and vagal deficits.

3. Large tumors may inflict other cranial nerve deficits.

Small tumors, which we consider to be equal to or smaller than $2 \mathrm{~cm}$ in diameter, are usually easily removed with a predictable morbidity that is limited to the vagus nerve only; and there may well be a preoperative deficit in any case. A large tumor carries with it higher surgical risks with the possibility of additional cranial nerve palsies and damage to the internal carotid artery. Modern imaging techniques allow accurate monitoring of tumor growth that allows a change of management plan before the risk of collateral damage becomes too great. Preoperative vagal palsy eliminates the problem of an acute postoperative palsy which is often the only real contraindication to surgery.

The age of the patient has to be weighed against the size of the tumor, predicted growth, and cranial nerve function. It may well be reasonable to adopt a watchful waiting policy in elderly patients who might not adapt well to an acute neural deficit. Multifocal paragangliomas present the surgeon and the patient with the greatest problem. The natural history of these tumors may result in a bilateral vagal palsy and make a pre-emptive surgical palsy unacceptable. In patients with bilateral paragangliomas 
Table 2 Parameters

\begin{tabular}{|c|c|c|}
\hline \multirow[b]{2}{*}{ Monofocal } & \multicolumn{2}{|c|}{ AGE $<60$} \\
\hline & Tenth CN Status & Treatment \\
\hline \multirow[t]{2}{*}{ SIZE $<2 \mathrm{~cm}$} & Tenth CN loss & Surgery \\
\hline & No tenth $\mathrm{CN}$ loss & Observation \\
\hline \multirow{3}{*}{ SIZE $>2 \mathrm{~cm}$ evolutive tumor } & Tenth CN loss & Surgery \\
\hline & No tenth $\mathrm{CN}$ loss & Observation \\
\hline & Tenth/No tenth CN loss & Surgery \\
\hline \multicolumn{3}{|l|}{ Plurifocal } \\
\hline \multirow{2}{*}{ SIZE $<2 \mathrm{~cm}$, nonevolutive } & Tenth CN loss & Surgery \\
\hline & No tenth $\mathrm{CN}$ loss & Observation \\
\hline \multirow[t]{2}{*}{ SIZE $>2 \mathrm{~cm}$, nonevolutive } & Tenth CN loss & Surgery \\
\hline & No tenth $\mathrm{CN}$ loss & Observation (or surgery)* \\
\hline \multirow[t]{3}{*}{ SIZE any, evolutive } & Tenth CN loss & Surgery \\
\hline & No tenth $\mathrm{CN}$ loss & Observation (or surgery)* \\
\hline & & \\
\hline \multirow[t]{2}{*}{ Monofocal/Plurifocal } & & $\begin{array}{l}\text { Observation (surgical morbidity } \\
>\text { natural morbidity) }\end{array}$ \\
\hline & & Surgery ${ }^{\dagger}$ \\
\hline
\end{tabular}

it is only acceptable to operate on the side with a pre-existing vagal palsy. It should always be remembered that a young patient with multiple paragangliomas may develop even more. A unilateral vagal tumor may become one of a pair in time. The decision to resect a vagal paraganglioma in this situation can never be taken lightly. The choice between surgery and watchful waiting is a balance between the natural actual or potential morbidity and the predictable surgical morbidity. Table 2 contains the guidelines of treatment based on this concept.

\section{CONCLUSION}

Vagal paragangliomas usually arise in the parapharyngeal space though there is evidence of cervical paragangliomas growing along the cervical course of the vagus. These tumors are easily diagnosed by MRI and, in some cases, with the addition of angiography. The cervicoparotid approach using microsurgical techniques gives safe access to the upper pole of the tumor with minimal risk to the lower cranial nerves and the internal carotid artery.

Management options for patients with these tumors include watchful waiting and surgery. The choice between these options is determined by consideration of the likely natural history, age of the patient, size of the tumor, and associated cranial nerve palsies. Surgical treatment of the vagal tumors in patients with multifocal disease should only be undertaken if it will not add to the patient's morbidity. Progress in molecular biology and genetics should help in the screening and treatment planning of familial cases.

\section{REFERENCES}

1. Ferlito A, Pesavento G, Recher G, Nicolai P, Narne S, Polidoro F. Assessment and treatment of neurogenic and non-neurogenic tumors of the parapharyngeal space. Head Neck Surg 1984;7:32-43

2. Jackson CG. Neurotologic skull base surgery for glomus tumors. Diagnosis for treatment planning and treatment options. Laryngoscope 1993;103(suppl):17-22 
3. Jansen JC. Paragangliomas of the Head and Neck. Clinical Implications of Growth Rate and Genetics. Enschede, Holland: Print Partners Ipskamp; 2001

4. Olsen KD. Tumors and surgery of the parapharyngeal space. Laryngoscope 1994;104(suppl):1-28

5. Thomassin JM, Deveze A, Marciano S. Paragangliomi laterocervicali. Encycl Méd Chir Otorinolaringoiatria 2003; 20-955-A-10

6. Thomassin JM, Deveze A, Laurent P, Esteve A, Branchereau A. Chirurgie des paragangliomes cervicaux. Encycl Méd Chir, Techniques chirurgicales, Tete et cou 2002;46500

7. Zanaret M, Guerrier B. Rapport de la société française d'oto-rhino-laryngologie et de chirurgie de la face et du cou. Paragangliomes cervicaux. In: Patologie vasculaire en ORL. Paris, France: Masson; 2000:351-375

8. Mazzoni A, Sanna M. Posterolateral approach to the skull base. The petro-occipital trans-sigmoid approach. Skull Base 1995;5:157-167

9. Deffrennes D, Bastian D, George B, Tran Ba Huy P. Anatomical bases of the surgical approach to the posterior foramen [in French]. Neurochirurgie 1985;31:352-354

10. George B, Laurian C. Surgical approach to the whole length of the vertebral artery with special reference to the third portion. Acta Neurochir (Wien) 1980;51:259272
11. Shahinian H, Dornier C, Fisch U. Parapharyngeal space tumors: the infratemporal fossa approach. Skull Base 1995; 5:73-81

12. Spector GJ, Ciralsky R, Maisel RH, Ogura JH. Multiple glomus tumors in the head and neck. Laryngoscope 1975; 85:1066-1075

13. Tumeurs nerveuses du cou. Encycl Méd Chir Oto-rhinolaryngologie 1994;20-875-C-10

14. Walsh RM, Leen EJ, Gleeson MJ, Shaheen OH. Malignant vagal paraganglioma. J Laryngol Otol 1997;111:83-88

15. Ward PH, Liu C, Vinuela F, Benton JR. Embolization: an adjunctive measure for removal of carotid body tumors. Laryngoscope 1988;98:1287-1291

16. Som PM, Sacher M, Stollman AL, Biller HR, Lawson W. Common tumors of the parapharyngeal space: refined imaging diagnosis. Radiology 1988;169:81-85

17. Urquhart AC, Johnson JT, Myers EN, Schecter GL. Glomus vagal: paraganglioma of the vagus nerve. Laryngoscope 1994;104:440-445

18. Miller FR, Wanamaker JR, Lavertu P, Wood BG. Magnetic resonance imaging and the management of parapharyngeal space tumors. Head Neck 1996;18:67-77

19. Netterville JL, Jackson CG, Miller FR, Wanamaker JR, Glasscock ME. Vagal paraganglioma: a review of 46 patients treated during a 20-year period. Arch Otolaryngol Head Neck Surg 1998;124:1133-1140 